\title{
From action planning and plan enactment to fruit consumption: moderated mediation effects
}

\author{
Stefanie Kasten ${ }^{1,2^{*}}$, Liesbeth van Osch ${ }^{1,2}$, Sander Matthijs Eggers ${ }^{1,2}$ and Hein de Vries ${ }^{1,2}$
}

\begin{abstract}
Objectives: Sufficient fruit consumption is beneficial for a healthy live. While many Dutch adults intent to eat the recommended amount of fruit, only $5-10 \%$ of the population actually adheres to the recommendation. One mechanism that can help to narrow this gap between intention and actual fruit consumption is action planning. However, action planning is only assumed to be effective if plans are enacted. This study assessed which action plans are made and enacted, and further aimed to investigate two main hypotheses: 1. the effect of action planning (at T1) on fruit consumption (at T2) is mediated by plan enactment (at T3); 2. positive intentions (2a), high self-efficacy (2b) and a strong habit to eat fruit (2c) enhance the mediation of plan enactment, whereas a strong habit to eat snacks (2d) hinders the mediation of plan enactment.

Methods: This study was a self-reported longitudinal online survey study. A total of 428 participants filled in a survey, measuring demographic factors (e.g. gender, age, education level), several socio-cognitive constructs (i.e. attitudes, self-efficacy, habit, action planning, plan enactment), and fruit consumption, at three points in time (baseline, after 1 month, and after 3 months). Mediation and moderated mediation analyses were used to investigate the planningplan enactment- fruit consumption relationship.
\end{abstract}

Results: Up to $70 \%$ of the participants reported to have enacted their T1 action plans at T2. Action planning on fruit consumption was fully mediated by plan enactment (Hypothesis 1). All four proposed moderators (i.e. intention, selfefficacy, habit to consume fruit, and habit to consume snacks) significantly influenced the mediation (Hypotheses 2a-2d). Mediation of plan enactment was only present with high levels of intention, high levels of self-efficacy, strong habits to eat fruit, and weak habits to eat snacks.

Conclusion: The study suggests the importance of plan enactment for fruit consumption. Furthermore, it emphasizes the necessity of facilitating factors. High levels of intention, self-efficacy and a strong habit to consume fruit clearly aid the enactment of action plans. This suggests that when these factors are moderately low, plan enactment may fail and thus an intervention may require first steps to foster these moderating factors.

Keywords: Fruit consumption, Action planning, Plan enactment, Moderated mediation

\footnotetext{
* Correspondence: s.kasten@maastrichtuniversity.nl

${ }^{1}$ Department of Health Promotion, Faculty of Health, Medicine and Life

Sciences, Maastricht University, PO Box 616, 6200 Maastricht, MD,

Netherlands

${ }^{2}$ CAPHRI-School for Public Health and Primary Care, Maastricht University,

Maastricht, Netherlands
}

(c) The Author(s). 2017 Open Access This article is distributed under the terms of the Creative Commons Attribution 4.0 International License (http://creativecommons.org/licenses/by/4.0/, which permits unrestricted use, distribution, and reproduction in any medium, provided you give appropriate credit to the original author(s) and the source, provide a link to the Creative Commons license, and indicate if changes were made. The Creative Commons Public Domain Dedication waiver (http://creativecommons.org/publicdomain/zero/1.0/) applies to the data made available in this article, unless otherwise stated. 


\section{Background}

A balanced diet based on low fat, vitamins, and fibers is beneficial for a healthy life and for maintaining body weight. To achieve such a diet the consumption of sufficient fruit and vegetables is essential. Fruit and vegetable products are the primary source of vitamines, minerals, and dietary fiber [1]. Studies have emphsized the importance of vegetable and fruit consumption with regard to the prevention of coronary heart disease, stroke, and hypertension. Additionally, fruit and vegetable consumption is inversely associated with overweight, type 2 diabetes mellitus, and even some forms of cancer [2]. To improve overall health the WHO (World Health Organisation) recomments a minimum of $400 \mathrm{~g}$ of fruit and vegetables per day for adults. However, amongst the Dutch adult population only $5 \%$ adheres to the guidelines for vegetable consumption and around $5-10 \%$ eats sufficient fruit [3-5]. While vegetables are mainly consumed during meals, fruit is mostly eaten between meals as a snack [5]. Aditionally to the critically low consumption of fruits and vegatables, the consumption of salt, often through the intake of salty snacks, is too high amongst the same population [4]. One option to reduce the intake of unhealthy snacks is to stimulate the consumption of fruit and thereby replace the high calorie dense snack with a healthy option [6, 7]. However, changing unhealthy dietary intake can be difficult, due to the fact that behaviour is highly influenced by several cognitive and environmental factors [8-10]. Cognitive determinants such as self-efficacy, intention, and habit have been studied to be important influential factors regarding healthy behaviour [11-13]. Although the impact of these factors on fruit consumption has been studied [14-16], little attention has been paid to their moderating effect on the process of behaviour change, and factors that have been shown to preceede and facilitate behaviour changes, such as intention and action planning.

Intention has long been regarded as the strongest and most proximal indicator for behavioural performance [17, 18]. Yet, studies show that people often fail to translate their good intentions into actions, a phenomenon widely known as the "intention-behaviour-gap" $[19,20]$. To close this gap between the intention to eat healthy and actually consuming a healthier diet, a number of theorists have put forward planning models and strategies [19, 21, 22].

Several health behaviour change theories such as the Health Action Process Approach [23] (HAPA) and the I-Change Model [24] illustrate how planning of specific actions ('action planning') can help to bridge the intentionbehaviour gap and therefore lead to more efficient behaviour change. Action planning refers to a process of creating a series of specific sub-actions to translate a person's intention into actions aimed at goal achievement [21, 25-28]. However, this is only the case when the action plans are enacted [28-30]. Even though goal setting implies both planning and plan enactment, little is known about the separate contributions of plan enactment to behaviour change regarding health behaviour [24, 29, 30]. De Vries et al. [28] investigated the mediating effect of plan enactment in the relationship between action planning and smoking cessation and showed that the effect of action planning on behaviour was fully mediated by enactment. The first goal of this study is therefore to replicate previous findings of de Vries et al. [28] with regard to fruit consumption. Based on their findings, we hypothesize that plan enactment will mediate the effect of planning on fruit consumption (hypothesis 1).

A second goal of this study pertains to assessing whether the planning process is influenced by other factors (hypotheses 2a-2d). We will concentrate on four factors (i.e. intention, self-efficacy, and fruit and snack habit) that are hypothesized to moderate the effects of plan enactment. The first proposed moderator is intention. Studies found that high intentions strengthen the effect of planning on behaviour [31] and that people with high intentions enact more plans and thereby enhance behaviour change $[28,30]$. Therefore, our second hypothesis is that the higher a person's intention, the stronger the mediation effect of plan enactment (hypothesis 2a). The second proposed moderator of plan enactment is selfefficacy. Models like the HAPA and the I-Change Model state the importance of self-efficacy regarding behaviour change [23, 24]. However, self-efficacy has not only been influential with regard to behaviour. While Sniehotta et al. [32] found that self-efficacy acts as a mediator between intention and behaviour, other studies found that selfefficacy is one of the strongest predictors for planning $[33,34]$ and the enactment of plans [35]. Furthermore, high self-efficacy is assumed to result in more perseverance to attain certain goals [36]. Consequently, we assume more mediation of plan enactment under high levels of self-efficacy (hypothesis 2b). The third proposed moderator is habit. Habits may show an oppositional influence on behaviour change. A strong habit regarding healthy behaviour enhances health behaviour [37-39], whereas a strong habit with regard to unhealthy behaviour can be a barrier to healthy behaviour change [40, 41]. This indicates that whereas strong unhealthy nutrition habits can be identified as barriers for behaviour change, the formation of healthy habits has been found to be a strong indicator for increased consumption of fruit and vegetables [37]. We therefore hypothesize that a strong habit to consume fruit would strengthen the mediation by plan enactment (hypothesis 2c), and a strong habit to snack would inhibit the mediation effect (hypothesis 2d).

Within this study, we firstly explore and describe which specific action plans regarding fruit consumption 
are made at $\mathrm{T} 1$ and which of these action plans are enacted at T2. Subsequently, we will depict the relationship between planning, plan enactment and fruit consumption. Afterwards, we will investigate this relationship in the context of several social cognitive variables. We will test the hypothesis that plan enactment mediates the effect of action planning on fruit consumption (hypothesis 1 ), and the hypotheses that high intention, high selfefficacy and a strong habit to eat fruit will enhance plan enactment, whereas a strong habit to eat snacks may hinder the enactment of action plans with regard to fruit consumption (moderated mediation hypotheses $2 \mathrm{a}-\mathrm{d}$ ).

\section{Methods}

\section{Participants and procedure}

The sample of the conducted study consisted of Dutch adults ( $>18$ years). All participants were registered members of an online survey panel (i.e. Flycatcher). Registration to the panel free of charge and can be done online. The panel contacts the members that are relevant for a specific study. In case of this study the panel contacted Dutch adults that were representative for the Dutch adult population with regard to gender, age, and educational level. There were no other inclusion criteria beside the minimum age of 18 . A total of 806 participants were invited by e-mail, to participate in the online study. The email consisted of an explanation that confidentiality would be ensured, that the proposed study would contain three waves of measurements, and that the completion of all three questionnaires would be rewarded with a small incentive (approximately $3 €$ ). Additionally, the e-mail contained a link that led participants to the online questionnaire. Informed consent was obtained from all individual participants included in the study.

At baseline measurement (T1), 574 respondents (71.0\%) completed the questionnaire. Four weeks later, at first follow-up (T2), 496 participants $(86.4 \%$ of baseline) filled in the questionnaire. Finally, a total of 428 participants ( $74.6 \%$ of baseline) also completed the second follow-up (T3), eight weeks after baseline.

The subjects of this study were neither subjected to procedures, required to follow rules of behaviour, nor did the study involved scientific medical research. Therefore the study did not fall under the scope of the WMO (Medical Research Involving Human Subjects Act) and ethical approval was not required.

\section{Questionnaire}

At baseline demographic variables, past fruit consumption behaviour, intention, self-efficacy, action plans and habit strength (regarding fruit and snack consumption) were measured. At T2 plan enactment was assessed, and at T3 the consumption of fruit was measured. All items were pre-tested by experts of the online panel. Items were tested on readability and comprehensiveness and adjusted accordingly.

\section{Demographics (T1)}

Participants were asked to indicate their gender, age and highest completed educational level. The educational level was classified as "low" (elementary education, medium general secondary education, preparatory vocational school, or lower vocational school), "medium" (higher general secondary education, preparatory academic education, or medium vocational school), and "high" (higher vocational school or university level).

\section{Intention (T1)}

Intention was measured by two items. The first item referred to the extent to which participants intended to consume two pieces of fruit daily. The second item added a time-reference, asking respondents to what extent they intended to consume fruit within the next month. Answering options for both items ranged from (1) "I definitely do not intend to" to (7) "I definitely intend to" (Cronbach's $\alpha=0.93)$. A mean score was calculated for further analyses.

\section{Self-efficacy (T1)}

Self-efficacy was assessed by four items to examine to what extent participants think they will be able to consume fruit in different situations [42], i.e. fruit consumption "during the week", "during the weekend", "when one is very busy", and "during the winter months" (Cronbach's $\alpha=0.91$ ). Answering options varied from (1) "I will certainly not be able to" to (7) "I will certainly be able to". Throughout the analyses the mean score was used.

\section{Habits (T1)}

Habit strength was measured for the habit of eating fruit and the habit of eating snacks. Snacks were defined as high-caloric snacks, which were divided into 5 categories: 1. Fatty snacks (e.g. pizza, hamburgers), 2. Salty snacks (e.g. potato chips, nuts), 3. Sugary snacks (e.g. cookies, cake), 4. Candy bars, and 5. Savory snacks (e.g. sausage, dices of cheese). Habit strength was measured by a subset of six items from the Self-Report Habit Index [43]. Statements beginning with either fruit or snack "consumption is something" were followed by "I do frequently", "I do automatically", "that would require effort not to do", "that belongs to my daily routine", "I have no need to think about doing", and "that's typically "me"" (fruit consumption: Cronbach's $\alpha=0.95$; snack consumption Cronbach's $\alpha=0.93$ ). Answering options ranged from (1) "I totally disagree" to (7) "I totally agree". A mean score was calculated and used throughout the analyses. 


\section{Action planning (T1)}

Action planning was measured by five items that were derived from expert consulting and literature review $[24,44,45]$. Participants were asked to what extent they planned to perform a variety of sub-behaviours or actions, in order to reach higher consumption of fruit. Action plans included "buying fruit", "eating fruit at a fixed time of the day", "putting a fruit basket on the table", "taking fruit along when leaving the house (e.g. to work)", and "replacing unhealthy snacks with fruit" (Cronbach's $\alpha=0.77$ ). Answering options varied from (1) "I am definitely not planning to" to (7) "I definitely plan to". For the purpose of the frequency analysis, the variable was recoded into $(0=$ categories 1 to 4$)$ plan was not made and $(1=$ categories 5 to 7$)$ plan was made. For further analyses a mean score was calculated.

\section{Plan enactment (T2)}

Plan enactment was assessed by five items, measuring the extent to which respondents had carried out the five action plans in the last month (Cronbach's $\alpha=0.61$ ). The question regarding buying more fruit could be answered on a scale from (1) "no, not more" to (4) "yes, a lot more", whereas the other four questions had answering options ranging from (1) "no, (almost) never" to (4) "yes, (almost) always". For the purpose of the frequencies variable was recoded into $(0=$ category 1$)$ plan was not enacted and ( $1=$ categories 2 to 4$)$ plan was enacted. For further analyses a mean score was calculated.

\section{Fruit consumption $(T 1, T 2)$}

The fruit consumption measurement was based on a validated questionnaire [46] and included two items regarding a) the number of days per week the participant usually consumes fruit ( 0 to 7$)$, and b) the average amount of fruit the participant consumes on each of these days. Multiplication of these two responses results in an accurate measure of the fruit consumption during a week.

\section{Statistical analysis}

For the statistical analysis IBM SPSS Statistics 20 was used. To maximize available information given by the collected data, pairwise deletion was used to control for missing observations. Descriptive analyses were executed to describe the sample with regards to the background variables (age, sex, educational level, baseline fruit consumption, action plans, and plan enactment (T2)). Crosstabs and chi-square values were calculated to investigate the proportion of people who made action plans (T1) and who enacted these action plans (T2). In order to get insight into the associations between the variables Pearson's correlation were calculated between outcome fruit consumption (T3), baseline fruit consumption (T1), action planning (T1), plan enactment (T2), intention (T1), self-efficacy (T1), habit of fruit consumption (T1), habit of snack consumption (T1), and each of the five action plans (T1) and plan enactments (T2) separately. With regard to hypothesis 1, mediation analysis was based on the INDIRECT macro recommended by Preacher and Hayes [41]. This technique measures the effect of an independent variable $(\mathrm{X})$ on a dependent variable $(\mathrm{Y})$ mediated by a mediator $(\mathrm{M})$. First, path $\mathrm{A}$ indicates the effect of $X$ on $M$. Path B, examines the effect of $M$ on $Y$. Path $C$ is the simple effect of the $X$ on $Y$ without controlling for $M$. Whereas $C^{\prime}$ is the coefficient of path $X \rightarrow Y$ after including $M$ in the model. The indirect effect of $X$ on $Y$ through $M$ is calculated by subtracting $C^{\prime}$ from $C$ (path $A B=C-C^{\prime}$ ) [47]. Mediation was tested with plan enactment as a mediator of the relationship between action plans and the outcome behaviour. Subsequently, moderated mediation was tested using MODMED macro as suggested by Preacher et al. [48]. Moderated mediation was examined for intention (hypothesis 2a), self-efficacy (hypothesis $2 \mathrm{~b}$ ), habit strength of eating fruit (hypothesis $2 \mathrm{c}$ ), and habit strength of eating snacks (hypothesis $2 \mathrm{~d}$ ). All analyses were adjusted for the background variables (i.e. gender, age, education and baseline fruit consumption).

\section{Results}

\section{Description of sample}

Background variables of participants are displayed in Table 1. In total, 574 participants filled out the online baseline questionnaire. The respondents' mean age was 47.8 years $(S D=15.98)$ and $53.3 \%$ were women. Most participants had a medium level of education (42.5\%) and the average fruit consumption per week at baseline was 8.3 pieces.

\section{Action planning and plan enactment frequencies}

Subsequently, frequency analysis was conducted to investigate which action plans have been made at $\mathrm{T} 1$ and which action plans were enacted at T2. Table 2 shows the percentages of participants that made action plans at $\mathrm{T} 1$ and enacted these action plans at T2. The plan to "take fruit along when leaving the house" was made most frequently (57.8\%). However, the plans to "eat fruit at a fixed moment during the day" (69.4\%) and to "take fruit along when leaving the house" (69.3\%) were most often enacted at T2 when made at $\mathrm{T} 1$.

\section{Correlates of plan enactment}

Correlations were calculated between outcome fruit consumption (T3), plan enactment (T2), baseline fruit consumption, action planning, intention, self-efficacy, habit of fruit consumption, habit of snack consumption, and each of the five action plans (T1) and plan enactment 
Table 1 Sample characteristics

\begin{tabular}{|c|c|c|c|}
\hline & At Baseline $T 1 \quad(N=574)$ & At first follow-up T2 $(N=496)$ & At second follow-up T3 $(N=428)$ \\
\hline Age in years: $M(S D$; Range) & $47.83(15.98 ; 19-87)$ & & \\
\hline Gender: female (\%) & 53.3 & & \\
\hline \multicolumn{4}{|l|}{ Education (\%): } \\
\hline Low & 26.3 & & \\
\hline Medium & 42.5 & & \\
\hline High & 31.2 & & \\
\hline Fruit consumption (pieces per week): M (SD) & $8.33(6.71)$ & & \\
\hline Intentiona: M (SD) & $5.20(1.41)$ & & \\
\hline Self-efficacy ${ }^{a}: M(S D)$ & $5.11(1.25)$ & & \\
\hline Habit to eat fruit ${ }^{\mathrm{a}}: M(S D)$ & $4.62(1.70)$ & & \\
\hline Habit to eat snacks ${ }^{\mathrm{a}}: M(S D)$ & $2.74(1.51)$ & & \\
\hline Action planning ${ }^{a}: M(S D)$ & $4.52(1.22)$ & & \\
\hline Plan enactment ${ }^{\mathrm{b}}: M(S D)$ & & $2.00(0.68)$ & \\
\hline Fruit consumption (pieces per week): M (SD) & & & $8.21(6.71)$ \\
\hline
\end{tabular}

${ }^{\text {a Measured on a scale ranging from } 1 \text { to } 7}$

${ }^{\mathrm{b}}$ Measured on a scale ranging from 1 to 4

(T2) items separately (see Table 3) to investigate the associations between all variables used in the analyses.

Our results show that planning to eat fruit at a fixed time, planning to take fruit along when leaving the house, and planning to replace unhealthy snacks by fruit displayed moderate correlations $(r=0.3-0.5)$ with the outcome behaviour, whereas plans to buy fruit and to place fruit on the table were only weakly correlated $(r<0.3)$. The strongest correlation between enactment of plans and the outcome variable was found between eating fruit at a fixed time, taking fruit along when leaving the house and replacing unhealthy snacks with fruit. Placing a fruit basket on a table was only weakly $(r<0.3)$ correlated, and the plan to buy fruit was not significantly correlated to the outcome. Furthermore, we explored the correlations of the moderating factors with later fruit consumption at T3. Baseline fruit consumption, habit of fruit consumption, self-efficacy, and plan enactment were strong $(r>0.5)$ to moderate $(0.5<r>0.3)$ positively correlated with fruit consumption at T3. Action planning and intention on the other hand showed weaker correlations $(r<0.3)$. Additionally, a weak $(r<-0.3)$ negative relationship between habit of snacking and fruit consumption at $\mathrm{T} 3$ was found.

Plan enactment mediates action planning and fruit consumption (hypothesis 1 )

To assess our first hypothesis, the mediation effect of plan enactment was investigated with the Preacher and Hayes technique (47). This analysis (see Fig. 1) yielded a significant effect of action planning on plan enactment ( $B=.27 ; 95 \% C I=.23-.31)$ and of plan enactment on fruit consumption $(B=1.72 ; 95 \% C I=.96-$ 2.48). Neither path $C(B=.12 ; 95 \% C I=-.23-.47)$ nor path $C^{\prime}(B=-.35 ; 95 \% C I=-.76-.06)$ indicated a significant effect of action planning on behaviour. However, results demonstrate that making action plans regarding fruit consumption at $\mathrm{T} 1$ led to a higher rate of plan enactment at $\mathrm{T} 2$, which subsequently affects the total fruit consumption measured at T3. This indicates

Table 2 Frequencies of action plans and their enactment

\begin{tabular}{lll}
\hline & $\begin{array}{c}\text { Participants that made } \\
\text { plan at T1 in \% (n) }\end{array}$ & $\begin{array}{c}\text { Participants that enacted } \\
\text { their plan at T2 in \% (n) }\end{array}$ \\
\hline Action plan 1: "I am planning to buy more fruit" & $54.4(312)$ & $50.0(156)$ \\
Action plan 2: "I am planning to eat fruit at a fixed time of the day" & $51.2(294)$ & $69.4(204)$ \\
Action plan 3: "I am planning to put a fruit basket on the table" & $45.8(263)$ & $65.8(173)$ \\
Action plan 4: "I am planning to take fruit along when leaving the house (e.g. to work)" & $57.8(332)$ & $69.3(230)$ \\
Action plan 5: "I am planning to replace unhealthy snacks with fruit" & $47.9(275)$ & $68.3(174)$
\end{tabular}


Table 3 Correlations of plan enactment

\begin{tabular}{|c|c|c|c|c|c|c|c|c|c|c|c|c|c|c|c|c|c|c|}
\hline Pearson correlation & 1 & 2 & 3 & 4 & 5 & 6 & 7 & 8 & 9 & 10 & 11 & 12 & 13 & 14 & 15 & 16 & 17 & 18 \\
\hline 1. Fruit consumption T3 & 1 & & & & & & & & & & & & & & & & & \\
\hline 2. Fruit consumption $\mathrm{T} 1$ & $.76^{\mathrm{c}}$ & 1 & & & & & & & & & & & & & & & & \\
\hline 3. Intention $\mathrm{T} 1$ & $.34^{c}$ & $.40^{c}$ & 1 & & & & & & & & & & & & & & & \\
\hline 4. Self-efficacy T1 & $.57^{\mathrm{C}}$ & $.63^{c}$ & $.54^{c}$ & 1 & & & & & & & & & & & & & & \\
\hline 5. Habit snack $T 1$ & $-.23^{c}$ & $-.21^{c}$ & -.07 & $-.26^{c}$ & 1 & & & & & & & & & & & & & \\
\hline 6. Habit fruit $\mathrm{T} 1$ & $.64^{c}$ & $.72^{c}$ & $.44^{c}$ & $.77^{\mathrm{c}}$ & $-.26^{\mathrm{c}}$ & 1 & & & & & & & & & & & & \\
\hline 7. Mean $A P^{a} T 1$ & $.31^{\mathrm{c}}$ & $.38^{c}$ & $.59^{c}$ & $.55^{\mathrm{c}}$ & -.06 & $.52^{c}$ & 1 & & & & & & & & & & & \\
\hline $\begin{array}{l}\text { 8. } A P^{a} 1 \text { : } \\
\text { Buying fruit } \mathrm{T} 1\end{array}$ & $.10^{c}$ & $.09^{c}$ & $.52^{c}$ & $.30^{c}$ & .02 & $.22^{c}$ & $.68^{c}$ & 1 & & & & & & & & & & \\
\hline $\begin{array}{l}\text { 9. } A P^{a} 2 \text { : } \\
\text { Eating fruit at a fixed time of day } T 1\end{array}$ & $.37^{c}$ & $.44^{c}$ & $.46^{c}$ & $.50^{c}$ & $-.10^{c}$ & $.46^{\mathrm{C}}$ & $.69^{c}$ & $.31^{c}$ & 1 & & & & & & & & & \\
\hline $\begin{array}{l}\text { 10. } \mathrm{AP}^{\mathrm{a}} \text { 3: } \\
\text { Putting a fruit basket on the Table } \mathrm{T} 1\end{array}$ & $.12^{c}$ & $.20^{c}$ & $.31^{c}$ & $.33^{\mathrm{c}}$ & -.08 & $.33^{c}$ & $.72^{\mathrm{c}}$ & $.35^{c}$ & $.35^{\mathrm{c}}$ & 1 & & & & & & & & \\
\hline $\begin{array}{l}\text { 11. } A P^{a} 4 \text { : } \\
\text { Taking fruit along when leaving the } \\
\text { house } T 1\end{array}$ & $.28^{c}$ & $.34^{c}$ & $.39^{c}$ & $.41^{\mathrm{c}}$ & -.03 & $.45^{\mathrm{c}}$ & $.77^{\mathrm{c}}$ & $.39^{\mathrm{c}}$ & $.46^{\mathrm{C}}$ & $.42^{c}$ & 1 & & & & & & & \\
\hline $\begin{array}{l}\text { 12. } \mathrm{AP}^{\mathrm{a}} 5 \text { : } \\
\text { Replacing unhealthy snacks with } \\
\text { fruit } \mathrm{T1}\end{array}$ & $.27^{c}$ & $29^{c}$ & $.48^{\mathrm{c}}$ & $.46^{\mathrm{C}}$ & -.03 & .40 & $.75^{\mathrm{c}}$ & $.49^{\mathrm{c}}$ & $.38^{c}$ & $.41^{\mathrm{c}}$ & $.47^{c}$ & 1 & & & & & & \\
\hline 13. Mean $P E^{b} T 2$ & $.46^{\mathrm{c}}$ & $.50^{c}$ & $.40^{c}$ & $.48^{c}$ & $-.14^{c}$ & $.55^{\mathrm{c}}$ & $.63^{c}$ & $.31^{\mathrm{c}}$ & $.43^{c}$ & $.50^{c}$ & $.55^{\mathrm{c}}$ & $.48^{\mathrm{c}}$ & 1 & & & & & \\
\hline 14. $P E^{b}$ of $A P^{a} 1 T 2$ & .07 & -.01 & $.18^{c}$ & .04 & .04 & .02 & $.28^{c}$ & $.42^{c}$ & .05 & $.18^{c}$ & $.16^{c}$ & $.24^{c}$ & $.42^{c}$ & 1 & & & & \\
\hline 15. $P E^{b}$ of $A P^{a} 2 T 2$ & $.53^{\mathrm{c}}$ & $.59^{c}$ & $.29^{c}$ & $.50^{c}$ & $-.22^{c}$ & .61 & $.38^{c}$ & .07 & $.52^{c}$ & $.19^{c}$ & $.33^{c}$ & $.25^{\mathrm{c}}$ & $.64^{c}$ & -.04 & 1 & & & \\
\hline 16. $P E^{b}$ of $A P^{a} 3 T 2$ & $.11^{\mathrm{c}}$ & $.17^{c}$ & $.16^{c}$ & $.18^{c}$ & -.07 & $.23^{c}$ & $.39^{c}$ & $.13^{c}$ & $.17^{c}$ & $.59^{c}$ & $.24^{c}$ & $.25^{c}$ & $.62^{c}$ & $.15^{\mathrm{c}}$ & $.19^{c}$ & 1 & & \\
\hline 17. $P E^{b}$ of $A P^{a} 4 T 2$ & $.33^{\mathrm{c}}$ & $.39^{c}$ & $.28^{c}$ & $.37^{c}$ & -.04 & $.42^{c}$ & $.46^{\mathrm{c}}$ & $.15^{\mathrm{c}}$ & $.30^{c}$ & $.24^{c}$ & $.62^{c}$ & $.33^{c}$ & $.73^{\mathrm{c}}$ & $.12^{c}$ & $.41^{\mathrm{c}}$ & $.23^{c}$ & 1 & \\
\hline 18. $\mathrm{PE}^{\mathrm{b}}$ of $\mathrm{AP}^{\mathrm{a}} 5 \mathrm{~T} 2$ & $.37^{c}$ & $.35^{c}$ & $.37^{c}$ & $.37^{c}$ & $-.11^{c}$ & $.38^{\mathrm{c}}$ & $.47^{c}$ & $.29^{c}$ & $.27^{c}$ & $.30^{c}$ & $.37^{c}$ & $.48^{c}$ & $.72^{\mathrm{c}}$ & $.30^{c}$ & $.32^{c}$ & $.36^{\mathrm{c}}$ & $.52^{c}$ & 1 \\
\hline
\end{tabular}

${ }^{\mathrm{a}} A P$ Action plan

${ }^{\mathrm{b}} P E$ Plan enactment

csig. at $a<.05$

that, although the sole act of planning did not have a direct influence on fruit consumption (path C), a significant indirect effect of action planning on fruit consumption via plan enactment was found $(B=.47$; $95 \% C I=.26-.71)$.
Moderated mediation effects of intention, self-efficacy and habit strength (hypotheses 2a-d)

Subsequently, we examined the potential moderated mediation effects using the MODMED macro as suggested by Preacher et al. [48]. Table 4 shows the size of the

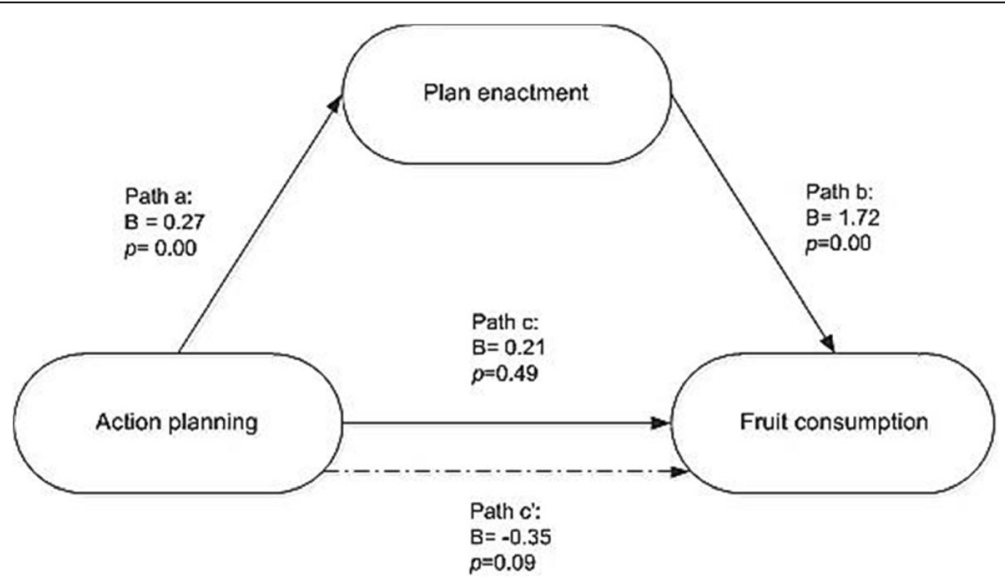

Fig. 1 Mediation effects of plan enactment 
indirect effect for each level of the moderator. The first proposed mediator was intention (hypothesis 2a). Results show a strong positive moderating effect for intention revealing that action plans made by participants at $\mathrm{T} 1$ were more often enacted when levels of intention were moderate or high (level $\geq 2$; cut-off level: $\beta=.49$; $95 \%$ $C I=.15-.94)$. Only, when intention was at the lowest level $($ level $=1)$ there was no significant moderation found. With regard to self-efficacy, the second moderator (hypothesis $2 \mathrm{~b}$ ), we found similar effects. Participants' action plans at T1 were more often enacted when a person scored high on self-efficacy (level $\geq 5$; cut-off level: $\beta=.39$; 95\% $C I=.19-.61)$. For low levels of selfefficacy, no significant mediation was present. With regard to habit, we hypothesized positive effects for habits to eat fruits (hypothesis 2c) and negative effects for an opposing habit, such as the habit to eat snacks (hypothesis 2d). For the habit to eat fruit a strong positive moderation was found when participants scored moderate or high (level $\geq 4$; cut-off level: $\beta=.23$; $95 \% C I=.04-.44$ ), indicating that a strong habit to eat fruit can enhance the enactment of action plans. On the other hand, for the habit to consume snacks results show that only when the habit was low to moderate (level $\leq 4$; cut-off level: $\beta=.28 ; 95 \% C I=.01-.56)$ enactment of action plans is enhanced.

\section{Discussion}

The importance of planning for health behaviour change has been investigated and proven across various health behaviours $[23,49,50]$. However, little research has been done concerning the significance of plan enactment and which factors may be associated with increased enactment.

Concerning the explorative analyses, our results reveal that between 50 to $70 \%$ of the participants reported to have enacted their T1 action plans at T2. Although the plan to "take fruit along when leaving the house" was made most frequently, the plan to "eat fruit at a fixed moment during the day" was most often enacted at T2. Furthermore, these two action plans also showed the strongest correlations with fruit consumption at T3. Even though the action plans to buy fruit and put fruit in a visible place have also been made and enacted often, both the planning and the enactment show only weak correlations with actual fruit consumption, indicating that these action plans are not strongly predictive of fruit consumption. A reason could be that people tend to buy fruit and may not consume it or only partly [51].

Our first hypothesis stated that the effect of action plans on fruit consumption would be mediated by plan enactment. Our findings showed that the effect of action planning on fruit consumption was fully mediated by plan enactment. This replicated findings of an earlier study showing that plan enactment mediated the effect of planning on smoking cessation behaviour [28]. Our results emphasize the importance of correct enactment of action plans when it comes to health behaviour change. This suggests that making specific action plans and executing them correctly can influence fruit consumption over the long term. Earlier research, as well as this study, indicates that guiding individuals to make plans is helpful but often insufficient for behaviour change when plans are not correctly or fully enacted $[28,52]$. The results indicate that action planning is only a part of the behaviour change and that without the enactment of the plans behaviour change is difficult to reach [13].

With regard to hypotheses 2 a-d stating that the mediation of plan enactment would be moderated by different factors, our findings identified significant moderation of the mediation effect through all four proposed moderators (i.e. intention, self-efficacy and fruit and snack habit). Our moderated mediation analyses revealed that the higher participants' intention was to consume fruit at baseline

Table 4 Regression models testing moderated mediation ${ }^{a}$

\begin{tabular}{|c|c|c|c|c|c|c|c|c|}
\hline & \multicolumn{8}{|c|}{ Moderators } \\
\hline & \multicolumn{2}{|c|}{ Intention } & \multicolumn{2}{|c|}{ Self-efficacy } & \multicolumn{2}{|c|}{ Habit Fruit } & \multicolumn{2}{|c|}{ Habit Snacks } \\
\hline & $\overline{\text { Coef }}$ & $95 \% \mathrm{Cl}$ & $\overline{\text { Coef }}$ & $95 \% \mathrm{Cl}$ & $\overline{\text { Coef }}$ & $95 \% \mathrm{Cl}$ & $\overline{\text { Coef }}$ & $95 \% \mathrm{Cl}$ \\
\hline \multicolumn{9}{|c|}{ Conditional indirect effects $^{\mathrm{b}}$} \\
\hline Level = 1 & .46 & $.05-1.02$ & -.05 & $-.56-.14$ & -.01 & $-.28-.16$ & $.70^{* * *}$ & $.37-1.08$ \\
\hline Level = 2 & $.49^{*}$ & $.15-.94$ & -.01 & $-.48-.20$ & .04 & $-.23-.23$ & $.54^{* * *}$ & $.31-.81$ \\
\hline Level $=3$ & $.51^{* *}$ & $.21-.88$ & .07 & $-.29-.32$ & .12 & $-.12-.31$ & $.40^{* * *}$ & $.18-.63$ \\
\hline Level $=4$ & $.53^{* * *}$ & $.29-.79$ & .21 & $-.07-.41$ & $.23^{*}$ & $04-.44$ & $.28^{*}$ & $.01-.56$ \\
\hline Level $=5$ & $.53^{* * *}$ & $.30-.78$ & $.39^{* * *}$ & $.19-.61$ & $.38^{* * *}$ & $.18-.62$ & .18 & $-.14-.54$ \\
\hline Level $=6$ & $.53^{* * *}$ & $.23-.87$ & $.61^{* * *}$ & $.35-.93$ & $.57^{* * *}$ & $.29-.90$ & .09 & $-.31-.51$ \\
\hline Level = 7 & $.51^{*}$ & $.07-1.00$ & $.89^{* * *}$ & $.43-1.43$ & $.79 * * *$ & $.37-1.29$ & .02 & $-.44-.50$ \\
\hline
\end{tabular}

${ }^{a}$ :Probed values based on the Johnson-Neyman technique, with bootstrapped confidence intervals (5000 samples)

b: All analysis were corrected for baseline fruit consumption, sex, age and educational level

${ }^{*} p<.05,{ }^{* *} p<.01,{ }^{* * *} p<.001$ 
the stronger was the mediating effect of plan enactment (hypothesis 2a). This indicates that high intentions can facilitate the enactment of action plans. There was no moderating effect found on the b-paths suggesting that when a plan has been enacted the effect on fruit consumption would not depend on the level of intention. These findings support our second hypothesis and are in line with findings of earlier studies about smoking cessation and sunscreen use [28].

Next, our results regarding the third hypothesis showed that the mediation effect of enactment between action planning and fruit consumption was stronger when a person's level of self-efficacy was also high (hypothesis $2 b$ ). These moderated mediation result support earlier findings showing that high levels of self-efficacy can act as an effective facilitator for behaviour change with regard to fruit and vegetable consumption [53], as well as an influential factor regarding goal achievement [12, 32, 34]. The results also replicate earlier findings by Lippke et al. [35], who indicated that when a person lacks self-efficacy, planning may be ineffective. However, no significant moderation was found concerning the b-path between enactment of action plans and fruit consumption indicating that independent from the level of self-efficacy the enactment of action plans is related to fruit consumption. This contradicts findings by Barz et al. [54]. Their study showed that the level of self-efficacy moderated the b-path between enactment of preparatory behaviours and the outcome behaviour, indicating that in the case of physical activity the use of preparatory actions would be more helpful for people with low self-efficacy. In other words, while the level of self-efficacy did not matter with regard to the enactment of a plan, high levels of selfefficacy were essential when it came to the translation of the enacted action plans into broader physical activity (e.g. making the plan to buy sport shoes led to buying shoes disregardful of the self-efficacy level, but buying sport shoes lead only to more physical activity when the level of selfefficacy was high). While our study did find support for moderation on the effect of action planning on enactment, the study by Barzet al. [54] found that self-efficacy moderates the effect of enactment on behaviour. This disparity could be explained by the differences in necessity of preparatory actions for each behaviour, and by the difficulty of these actions [54-56]. This indicates that more research is needed with regard to different health behaviours. Furthermore, the contrast in findings emphasizes the need for more research with regard to plan enactment and moderators across different health behaviours.

Third, we expected and found that the stronger a participant's habit to eat fruit the more likely it was that action plans were enacted (hypothesis 2c). Furthermore, a reversed moderating effect was found for the habit to eat snacks, meaning that only when the habit to eat snacks is weak, a significant mediation effect is found (hypothesis $2 \mathrm{~d}$ ). The results imply that action planning is less effective when opposing habits exist. Our results are in line with earlier studies [57-60] and show that action planning is helpful when increasing already habitual behaviour [40, 61, 62]. However, action planning alone might not be sufficient to change behaviour when a person has a strong antagonizing habit $[58,59]$. There was no moderating effect found for the b-path, indicating that as soon as a plan has been enacted habit has no significant effect on the plan enactment-behaviour relationship.

These results propose that it is important to understand under which conditions plans are enacted (e.g. high intention, high self-efficacy, and a strong habit to eat fruit). Interventions need to ensure that these fostering conditions are fulfilled to assure behaviour change. This suggests that when these factors are moderately low, plan enactment may fail and thus an intervention may require first steps to booster these moderating factors. Research therefore needs to focus on possibilities to monitor and follow-up on the enactment of plans during an intervention more closely. Additionaly, the identification of factors such as selfefficacy and intention facilitating or hindering plan enactment need further attention in order to make action planning interventions more effective.

Some limitations to our study should be mentioned. First, within our study no differences in specificity or quality of the action plans made were assessed. Previous studies showed that the more specific a plan is, the greater its predictive value $[27,63]$. This leads to the assumption that more specific and higher quality action plans would also lead to more enactment, a hypothesis that needs to be substantiated in future studies. Second, in our study we made no differentiation of plan enactment per plan, meaning that we only investigated the overall effect of making action plans and enacting them. Looking at each plan separately could give us further insight in which action plans are more often enacted and are more likely to be influenced by third factors such as intention or habit.

Furthermore, we did not differentiate between conditional (e.g. if situation $Y$ occurs I will do $X$ ) and unconditional plans (e.g. I will do $X$, independent of any situation $Y$ ). Sniehotta [64] argues that the distinction is necessary to understand the exact effect of planning on behaviour. Some studies have demonstrated the effectiveness of conditional plans with regard to behaviour change $[65,66]$. Yet, other research has shown that making more specific conditional plans (e.g. If I leave my house at 8:00 am, then I will take an apple) might not be suitable for unconditional behaviour change, because when situation Y does not occur the action will not be triggered and thereby the behaviour is unaffected [64]. This leads to the assumption that unconditional plans may have a greater effect on behaviour change because 
their effect is not bound to specific contexts. However, in order to test the process of planning and the importance of the working mechanism of the planning-enactmentbehaviour relationship further research is needed to determine whether it will also be important to discriminate between conditional and unconditional plans.

Another limitation that needs to be mentioned is that fruit consumption was measured in pieces of fruit that were consumed per day. While this method is validated [46] one can argue that nowadays a lot of fruit is consumed in forms of juices, sauces or even stewed. However research shows that most health effects can be found when fruits are consumed solid and fresh [67]. An additional limitation is the relative high dropout rate. While online surveys are relatively easy to conduct and often cost-effective the anonymity and lack of direct contact between participants and researcher can lead to lower response rates [68]. Other reasons for high dropout can be the questionnaire lengths or level of interest of the participants in the study topic. However, even though the dropout rate was relatively high, the sample was in terms of gender, age and educational level still representative for our population. Finally, within this study no control group was included. The inclusion would have led to a clearer picture about the effectiveness of the plans and their enactment.

The present study contributes to current research of fruit consumption, in particular with regard to the importance of plan enactment. Evidence is provided, that action planning alone is not automatically beneficial to behaviour change and that whether or not a person enacts a plan is dependent on levels of intention, self-efficacy and habit. Furthermore, our results support findings with regard to mediation and moderation in other health behaviour domains such as action control with regard to physical activity [34], condom use [69], physical activity [54] and smoking cessation [28].

\section{Conclusion}

The results of this study indicate the important role of plan enactment in fruit consumption, but also show that enactment of action plans is often suboptimal and depends on factors such as intention, self-efficacy, and habit. Furthermore, the results show that when action plans are not enacted behaviour change is less likely to occur [29]. The study suggests that interventions should not only target the construction of action plans, but also should monitor and support the enactment of these action plans, by for example sending reminders or boosters. Furthermore, the moderated mediation effects suggest that planning interventions should consider other factors such as intention, self-efficacy, and antagonistic habit to ensure that action planning actually leads to behaviour change. To further substantiate these findings and to strengthen the foundation of plan enactment further research, both for verification and generalization would be necessary.
Abbreviations

AP: Action plans; HAPA: Health Action Process Approach; PE: Plan enactment

Acknowledgements

Not applicable.

\section{Funding}

This study was financially supported by a grant of the Dutch Cancer Society (KWF Kankerbestrijding).

\section{Availability of data and materials}

The dataset used and analysed during the current study is available from the corresponding author on reasonable request.

\section{Authors' contributions}

Stefanie Kasten actively contributed to the preparation, analysis and interpretation of data, and led the manuscript development. Liesbeth van Osch provided the data, actively contributed to the development of the manuscript, interpretation of data, and added substantial inputs by critically reviewing and revising the draft manuscripts for improvement. Sander Matthijs Eggers actively contributed to the statistical analyses and participated in the development of the manuscript by critically reviewing and revising the draft manuscripts. Hein de Vries was involved in the data interpretation, and added substantial inputs by critically reviewing and revising the draft manuscripts. All authors read and approved the final manuscript.

\section{Ethics approval and consent to participate}

All procedures performed in studies involving human participants were in accordance with the ethical standards of the institutional and/or national research committee and with the 1964 Helsinki declaration and its later amendments or comparable ethical standards. The subjects of this study were neither subjected to procedures, required to follow rules of behaviour, nor did the study involved scientific medical research. Therefore the study did not fall under the scope of the WMO (Medical Research Involving Human Subjects Act) and ethical approval was not required. Due to the fact that the study did not fall under the scope of the WMO, no written informed consent was obtained from the human subjects. All participants were registered members of an online survey panel (i.e. Flycatcher). Flycatcher obtains online consent of the subjects to be part of the online panel with a 'Double-active opt-in' approach. Participants were allowed to leave the panel whenever they would like to.

\section{Consent for publication}

Not applicable.

\section{Competing interests}

All authors declare that they have no conflict of interest. However, it is worth mentioning that Hein de Vries is also scientific director of Vision2Health, a company implementing evidence based eHealth programs.

\section{Publisher's Note}

Springer Nature remains neutral with regard to jurisdictional claims in published maps and institutional affiliations.

Received: 4 January 2017 Accepted: 6 October 2017

Published online: 23 October 2017

\section{References}

1. World Health Organization. Increasing fruit and vegetable consumption to reduce the risk of non-communicable diseases. http://www.who.int/elena/ titles/fruit_vegetables_ncds/en/. 2015. Accessed 10 July 2017.

2. Boeing $H$, Bechthold $A$, Bub A, Ellinger S, Haller D, Kroke A, et al. Critical review: vegetables and fruit in the prevention of chronic diseases. Eur J Nutr. 2012;51(6):637-63.

3. Central office for Statistics (Originally Dutch: Centraal bureau voor de Statistiek, CBS). Lifestyle and health measurements during the Dutch public health congress. (Originally Dutch: Leefstijl en gezondheidsmetingen tijdens het Nederlands Congres Volksgezondheid). 2015. https://www.cbs.nl/nl-nl/ nieuws/2015/15/leefstijl-engezondheidsmetingen-tijdens-het-nederlandscongres-volksgezondheid. Accessed 10 July 2017. 
4. Public health care (Originally Dutch: Volksgezondheidenzorg, RIVM). Average consumption of adults and percentage that eats according to the guidelines for good nutrition.(Originally Dutch: Gemiddelde consumptie volwassenen en percentage dat eet volgens de Richtlijnen goede voeding.) https://www.volksgezondheidenzorg.info/onderwerp/voeding/cijferscontext/trends\#!node-trend-consumptie-van-fruit. Accessed 10 July 2017.

5. van der Sluis AA, Stijnen DAJM, Maaskant AJ, Zeinstra GG, Vingerhoeds MH, Heuts F, Heijnen J. On the way to a higher fruit and vegetable consumption: barriers and success factors: initial inventory and exploration of knowledge and most promissing interventions about increasing fruit and vegetable consumption (originally Dutch: op weg naar een hogere groente-en fruitconsumptie: barrières en succesfactoren: eerste inventarisatie en verkenning van kennis en meest kansrijke interventies rondom het verhogen groente-en fruitconsumptie). (no. 1431). Wageningen: UR food \& biobased; 2013

6. Luszczynska A, Horodyska K, Zarychta K, Liszewska N, Knoll N, Scholz U. Planning and self-efficacy interventions encouraging replacing energydense foods intake with fruit and vegetable: a longitudinal experimental study. Psychol Health. 2016;31(1):40-64.

7. van Osch L, Beenackers M, Reubsaet A, Lechner L, Candel M, de Vries H. Action planning as predictor of health protective and health risk behavior: an investigation of fruit and snack consumption. Int J Behav Nutr Phys Act. 2009:6(1):69.

8. Baranowski T, Perry CL, Parcel GS. How individuals, environments, and health behavior interact. Health behavior and health education: Theory, research, and practice. 2002;3:165-84.

9. Deshpande S, Basil MD, Basil DZ. Factors influencing healthy eating habits among college students: an application of the health belief model. Health Mark Q. 2009;26(2):145-64.

10. Story M, Kaphingst KM, Robinson-O'Brien R, Glanz K. Creating healthy food and eating environments: policy and environmental approaches. Annu Rev Public Health. 2008;29:253-72.

11. Olander EK, Fletcher H, Williams S, Atkinson L, Turner A, French DP. What are the most effective techniques in changing obese individuals' physical activity self-efficacy and behaviour: a systematic review and meta-analysis. Int J Behav Nutr Phys Act. 2013;10(1):1.

12. Kreausukon P, Gellert P, Lippke S, Schwarzer R. Planning and self-efficacy can increase fruit and vegetable consumption: a randomized controlled trial. J Behav Med. 2012;35(4):443-51.

13. Lippke S, Ziegelmann JP, Schwarzer R. Initiation and maintenance of physical exercise: stage-specific effects of a planning intervention. Research in Sports Medicine. 2004;12(3):221-40.

14. Brug J, de Vet E, de Nooijer J, Verplanken B. Predicting fruit consumption: cognitions, intention, and habits. J Nutr Educ Behav. 2006;38(2):73-81.

15. de Bruijn G-J. Understanding college students' fruit consumption. Integrating habit strength in the theory of planned behaviour. Appetite. 2010;54(1):16-22.

16. Luszczynska A, Tryburcy M, Schwarzer R. Improving fruit and vegetable consumption: a self-efficacy intervention compared with a combined selfefficacy and planning intervention. Health Educ Res. 2007;22(5):630-8.

17. Ajzen I. The theory of planned behavior. Organ Behav Hum Decis Process. 1991;50(2):179-211.

18. Bandura A. Social cognitive theory of self-regulation. Organ Behav Hum Decis Process. 1991;50(2):248-87.

19. Godin G, Conner M. Intention-behavior relationship based on epidemiologic indices: an application to physical activity. Am J Health Promot. 2008;22(3): 180-2.

20. Sheeran P. Intention - behavior relations: a conceptual and empirical review. Eur Rev Soc Psychol. 2002;12(1):1-36.

21. Bagozzi RP. The self-regulation of attitudes, intentions, and behavior. Soc Psychol Q. 1992:178-204

22. Gollwitzer PM. Implementation intentions: strong effects of simple plans. Am Psychol. 1999;54(7):493.

23. Schwarzer R. Modeling health behavior change: how to predict and modify the adoption and maintenance of health behaviors. Appl Psychol. 2008; 57(1):1-29.

24. de Vries H, Kremers S, Smeets T, Brug J, Eijmael K. The effectiveness of tailored feedback and action plans in an intervention addressing multiple health behaviors. Am J Health Promot. 2008;22(6):417-25.

25. Austin JT, Vancouver JB. Goal constructs in psychology: structure, process, and content. Psychol Bull. 1996;120(3):338.
26. Locke E, Latham G. Goal-setting theory. 1994.

27. Elfeddali I, Bolman C, Candel MJ, Wiers RW, De Vries H. The role of selfefficacy, recovery self-efficacy, and preparatory planning in predicting shortterm smoking relapse. Br J Health Psychol. 2012:17(1):185-201.

28. de Vries H, Eggers SM, Bolman C. The role of action planning and plan enactment for smoking cessation. BMC Public Health. 2013;13(1):1.

29. Dholakia UM, Bagozzi RP, Gopinath M. How formulating implementation plans and remembering past actions facilitate the enactment of effortful decisions. J Behav Decis Mak. 2007;20(4):343-64.

30. Verbiest ME, Presseau J, Chavannes NH, Scharloo M, Kaptein AA, Assendelft WJ, et al. Use of action planning to increase provision of smoking cessation care by general practitioners: role of plan specificity and enactment. Implement Sci. 2014;9(1):1.

31. Wiedemann AU, Schüz B, Sniehotta F, Scholz U, Schwarzer R. Disentangling the relation between intentions, planning, and behaviour: a moderated mediation analysis. Psychol Health. 2009;24(1):67-79.

32. Sniehotta FF, Scholz U, Schwarzer R. Bridging the intention-behaviour gap: planning, self-efficacy, and action control in the adoption and maintenance of physical exercise. Psychol Health. 2005;20(2):143-60.

33. Luszczynska A, Schwarzer R. Planning and self-efficacy in the adoption and maintenance of breast self-examination: a longitudinal study on selfregulatory cognitions. Psychol Health. 2003;18(1):93-108.

34. Luszczynska A, Schwarzer R, Lippke S, Mazurkiewicz M. Self-efficacy as a moderator of the planning-behaviour relationship in interventions designed to promote physical activity. Psychol Health. 2011;26(2):151-66.

35. Lippke S, Wiedemann AU, Ziegelmann JP, Reuter T, Schwarzer R. Selfefficacy moderates the mediation of intentions into behavior via plans. Am J Health Behav. 2009:33(5):521-9.

36. Locke EA, Latham GP. New developments in goal setting and task performance. Routledge; 2013.

37. Lally P, Chipperfield A, Wardle J. Healthy habits: efficacy of simple advice on weight control based on a habit-formation model. Int J Obes. 2008;32(4):700-7.

38. Lally P, Gardner B. Promoting habit formation. Health Psychol Rev. 2013; 7(sup 1):S137-S58.

39. de Bruijn G-J, Rhodes RE, van Osch L. Does action planning moderate the intention-habit interaction in the exercise domain? A three-way interaction analysis investigation. J Behav Med. 2012;35(5):509-19.

40. de Bruijn G-J, Kremers SP, de Vet E, de Nooijer J, Van Mechelen W, Brug J. Does habit strength moderate the intention-behaviour relationship in the theory of planned behaviour? The case of fruit consumption. Psychol Health. 2007;22(8):899-916.

41. Jager W. Breaking bad habits: a dynamical perspective on habit formation and change. Human decision-making and environmental perceptionunderstanding and assisting human decision-making in real life settings Libor Amicorum for Charles Vlek. Groningen: University of Groningen; 2003.

42. Brug J, Lechner L, De Vries H. Psychosocial determinants of fruit and vegetable consumption. Appetite. 1995;25(3):285-96.

43. Verplanken B, Orbell S. Reflections on past behavior: a self-report index of habit Strength1. J Appl Soc Psychol. 2003;33(6):1313-30.

44. Cullen KW, Baranowski T, Smith SP. Using goal setting as a strategy for dietary behavior change. J Am Diet Assoc. 2001;101(5):562-6.

45. Nothwehr F, Denni L, Measurement WH. Of behavioral objectives for weight management. Health Educ Behav. 2007;34(5):793-809.

46. Van den Brink C, Ocke M, Houben A, Van Nierop P, Droomers M. Validation of a standard questionnaire for nutrition for local and national public health monitor. In: (Originally Dutch: Validering van standaardvraagstelling voeding voor Lokale en Nationale Monitor Volksgezondheid.) RIVM rapport 260854008; 2005.

47. Preacher KJ, Hayes AF. SPSS and SAS procedures for estimating indirect effects in simple mediation models. Behav Res Methods Instrum Comput. 2004;36(4):717-31.

48. Preacher KJ, Rucker DD, Hayes AF. Addressing moderated mediation hypotheses: theory, methods, and prescriptions. Multivar Behav Res. 2007;42(1):185-227.

49. Sniehotta FF, Schwarzer R, Scholz U, Schüz B. Action planning and coping planning for long-term lifestyle change: theory and assessment. Eur J Soc Psychol. 2005;35(4):565-76.

50. Osch L, Reubsaet A, Lechner L, Beenackers M, Candel M, Vries H. Planning health behaviour change: comparing the behavioural influence of two types of self-regulatory planning. Br J Health Psychol. 2010;15(1):133-49.

51. Government of the Netherlands. Facts and figures on consumer's food waste in 2013. In: Originally Dutch: Feiten en cijfers verspilling voedsel 
consumenten in 2013; 2014. https://www.rijksoverheid.nl/documenten/ brochures/2014/01/29/feiten-en-cijfers-verspilling-voedsel-consumenten-in2013. Accessed 06 June 2016.

52. de Hoog N, Bolman C, Berndt N, Kers E, Mudde A, de Vries H, et al. Smoking cessation in cardiac patients: the influence of action plans, coping plans and self-efficacy on quitting smoking. Health Educ Res. 2016;31(3):350-62.

53. Richert J, Reuter T, Wiedemann AU, Lippke S, Ziegelmann J, Schwarzer R. Differential effects of planning and self-efficacy on fruit and vegetable consumption. Appetite. 2010;54(3):611-4.

54. Barz M, Lange D, Parschau L, Lonsdale C, Knoll N, Schwarzer R. Self-efficacy, planning, and preparatory behaviours as joint predictors of physical activity: a conditional process analysis. Psychol Health. 2016;31(1):65-78.

55. Koring M, Parschau L, Lange D, Fleig L, Knoll N, Schwarzer R. Preparing for physical activity: pedometer acquisition as a self-regulatory strategy. Applied Psychology: Health and Well-Being. 2013;5(1):136-47.

56. Chapman J, Armitage CJ. Do techniques that increase fruit intake also increase vegetable intake? Evidence from a comparison of two implementation intention interventions. Appetite. 2012;58(1):28-33.

57. Webb TL, Sheeran P, Luszczynska A. Planning to break unwanted habits: habit strength moderates implementation intention effects on behaviour change. Br J Soc Psychol. 2009;48(3):507-23.

58. Adriaanse MA, Oettingen G, Gollwitzer PM, Hennes EP, De Ridder DT, De Wit JB. When planning is not enough: fighting unhealthy snacking habits by mental contrasting with implementation intentions (MCII). Eur J Soc Psychol. 2010;40(7):1277-93.

59. Adriaanse MA, van Oosten JM, de Ridder DT, de Wit JB, Evers C. Planning what not to eat: ironic effects of implementation intentions negating unhealthy habits. Personal Soc Psychol Bull. 2011;37(1):69-81.

60. Turconi G, Guarcello M, Maccarini L, Cignoli F, Setti S, Bazzano R, et al. Eating habits and behaviors, physical activity, nutritional and food safety knowledge and beliefs in an adolescent Italian population. J Am Coll Nutr. 2008;27(1):31-43.

61. Holland RW, Aarts H, Langendam D. Breaking and creating habits on the working floor: a field-experiment on the power of implementation intentions. J Exp Soc Psychol. 2006:42(6):776-83.

62. Verplanken B, Wood W. Interventions to break and create consumer habits. J Publ Policy \& Marketing. 2006:25(1):90-103.

63. Lv O, Lechner $L$, Reubsaet A, Vries HD. From theory to practice: an explorative study into the instrumentality and specificity of implementation intentions. Psychol Health. 2010;25(3):351-64.

64. Sniehotta FF. Towards a theory of intentional behaviour change: plans, planning, and self-regulation. Br J Health Psychol. 2009;14(2):261-73.

65. Milne $S$, Orbell S, Sheeran P. Combining motivational and volitional interventions to promote exercise participation: protection motivation theory and implementation intentions. Br J Health Psychol. 2002;7(2):163-84.

66. Sniehotta FF, Scholz U, Schwarzer R. Action plans and coping plans for physical exercise: a longitudinal intervention study in cardiac rehabilitation. Br J Health Psychol. 2006:11(1):23-37.

67. Flood-Obbagy JE, Rolls BJ. The effect of fruit in different forms on energy intake and satiety at a meal. Appetite. 2009;52(2):416-22.

68. Galesic M. Dropouts on the web: effects of interest and burden experienced during an online survey. J Off Stat. 2006;22(2):313.

69. Bryan A, Fisher JD, Fisher WA. Tests of the mediational role of preparatory safer sexual behavior in the context of the theory of planned behavior. Health Psychol. 2002;21(1):71

\section{Submit your next manuscript to BioMed Central and we will help you at every step:}

- We accept pre-submission inquiries

- Our selector tool helps you to find the most relevant journal

- We provide round the clock customer support

- Convenient online submission

- Thorough peer review

- Inclusion in PubMed and all major indexing services

- Maximum visibility for your research

Submit your manuscript at www.biomedcentral.com/submit 